\title{
Burden of spousal caregivers of stage II and III esophageal cancer survivors 3 years after treatment with curative intent
}

\author{
N. Haj Mohammad ${ }^{1}$ - A. W. Walter ${ }^{1}$ - M. G. H. van Oijen ${ }^{1}$ • M. C. C. M. Hulshof ${ }^{2}$ \\ J. J. G. H. M. Bergman ${ }^{3}$ • M. C. J. Anderegg ${ }^{4}$ • M. I. van Berge Henegouwen ${ }^{4}$. \\ I. Henselmans ${ }^{5}$ - M. A. G. Sprangers ${ }^{5}$ - H. W. M. van Laarhoven ${ }^{1}$
}

Received: 17 October 2014 / Accepted: 29 March 2015 / Published online: 18 April 2015

(C) The Author(s) 2015. This article is published with open access at Springerlink.com

\begin{abstract}
Objectives The aim of this study is to examine caregiver burden of spousal caregivers of patients with esophageal cancer after curative treatment with neoadjuvant chemoradiation followed by resection and to assess factors associated with caregiver burden.

Methods In this exploratory, cross-sectional study, spousal caregivers and patients were eligible if the caregiver was the patient's spouse and the patient had been treated with chemoradiation followed by surgery after esophageal carcinoma diagnosis. Forty-seven couples were included. Spousal caregivers completed a questionnaire, examining caregivers' burden (Self-Perceived Pressure from Informal Care (SPPIC, Dutch)), caregiver unmet needs (SCNS-
\end{abstract}

Electronic supplementary material The online version of this article (doi:10.1007/s00520-015-2727-4) contains supplementary material, which is available to authorized users.

N. Haj Mohammad

n.hajmohammad@amc.nl

1 Department of Medical Oncology, Academic Medical Center, University of Amsterdam, F4-222, Meibergdreef 9, PO box 22600, 1100 DD Amsterdam, The Netherlands

2 Department of Radiation Oncology, Academic Medical Center, University of Amsterdam, Amsterdam, The Netherlands

3 Department of Gastroenterology, Academic Medical Center, University of Amsterdam, Amsterdam, The Netherlands

4 Department of Surgery, Academic Medical Center, University of Amsterdam, Amsterdam, The Netherlands

5 Department of Medical Psychology, Academic Medical Center, University of Amsterdam, Amsterdam, The Netherlands
P\&S), anxiety and depression (Hospital Anxiety and Depression Scale (HADS)), and marital satisfaction (Maudsley Marital Questionnaire (MMQ)). Patients completed the latter two questionnaires and a cancer specific quality of life questionnaire (EORTC-QLQ C30 and OES18 (oesophageal module). Logistic regression analysis was performed to identify correlates for caregiver burden.

Results The median time after esophagectomy was 38 months. Thirty-four percent of the spousal caregivers reported moderate or high burden. Spousal caregivers most frequently reported unmet needs were managing concerns about the cancer coming back (43\%), dealing with others not acknowledging the impact on your life of caring for a person with cancer (38\%), and balancing the needs of the person with cancer and one's own needs. A comparable proportion of spousal caregivers and patients showed symptoms of anxiety (23 vs $17 \%$ ) and depression (17 vs $17 \%$ ). Spousal caregivers reported significantly more dissatisfaction than patients on the marital scale $(p<0.01)$. Factors independently associated with higher caregiver burden were fatigue of the patient $(\mathrm{OR}=1.66$, $95 \%$ CI 1.12-2.47) and depression of the spousal caregiver $(\mathrm{OR}=1.44,95 \% \mathrm{CI} 1.11-1.86)$.

Conclusions More than a third of the spousal caregivers of patients with esophageal cancer treated with curative intent report moderate or high burden 3 years after treatment. Fatigue of the patient and depression of the spousal caregiver are associated with caregiver burden. To improve clinical care, identification of spousal caregivers at risk for experiencing higher caregiver burden and implementation of specific interventions is needed.

Keywords Esophageal cancer · Caregiver · Burden Unmet needs 


\section{Introduction}

Esophageal cancer is the eighth most common cancer and ranks sixth on the list of cancer mortality causes [1]. In the last two decades, the incidence of esophageal cancer has increased [2].

Patients with resectable disease that are deemed fit for surgery are treated by multimodality treatment including chemotherapy, radiation, and surgery [3]. Although this is curative intent treatment, the prognosis is poor with a 5 -year survival rate of $50 \%$ [4].

This treatment may come at the cost of a substantial reduction in quality of life (QOL) and daily functioning. For example, after an esophageal resection, patients need to eat more frequently, which may imply that spousal caregivers have to reorganize their daily activities to provide frequent meals in the course of the day. Also, the particularly poor prognosis may have a large impact on caregiver burden. However, in esophageal cancer, this has not been a topic of study yet. Currently, research on quality of life after esophageal cancer treatment focuses on the patient who underwent the treatment. However, more than $50 \%$ of the diagnosed cancer patients are cared for by a loved one, mostly aspousal caregiver or adult children $[5,6]$.

From previous studies, it is well known that informal care giving to patients with chronic disease, including cancer, may significantly affect health and well-being of spousal caregivers [7-11].

\section{Caregiver burden}

Having to care for a loved one may induce caregiver burden. Caregiver burden is defined as the extent to which caregivers feel that their emotional or physical health, social life, and financial status have suffered as a result of caring [12].

Caregiver burden is influenced by characteristics and health of the patient and caregiver diagnosis, treatment, stage of disease, and amount of caregiving-related tasks [10, 13, 14] (Fig. 1).

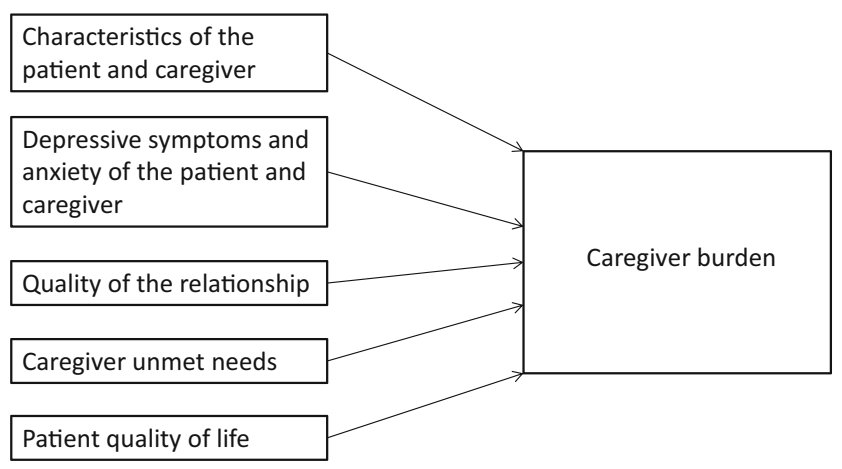

Fig. 1 Factors influencing caregiver burden

\section{Characteristics of the spousal caregiver and the patient}

Women of a younger age have consistently been found to perceive caregiving as more negative $[15,16]$. Other demographic characteristics, such as education, income, and employment status, have been less studied, but have equally significant implications in cancer caregiver burden. With regard to patient characteristics, studies have found that poorer health was associated with more negative experiences of caregiving $[17,18]$.

\section{Emotional health}

The most frequently reported problems of caregivers of cancer patients reside in the psychological domain, such as anxiety and depression. In a previous study among 101 caregivers of patients with advanced gastrointestinal cancer or lung cancer, almost $40 \%$ of the caregivers had depressive symptoms that were clinically relevant $[19,20]$. In a study among 75 caregivers of patients with brain tumors ( $75 \%$ of the malignant type), the prevalence of anxiety was $40 \%$ among caregivers [21].

Caregivers at increased risk of anxiety and depression report high levels of unmet needs. Unmet needs have been defined as "the difference between the services or support required dealing with a particular challenge and the actual services or support received" [22, 23].

\section{Relationship/social}

Distress in couples coping with cancer demonstrated that women consistently report more distress than men, regardless of whether they are the patient or the healthy partner in the couple [24]. Also, several studies have shown that marital dissatisfaction contributes to distress of spouse caregivers of cancer patients $[19,25,26]$.

\section{Unmet needs}

In a study of 193 patients of whom approximately one third was diagnosed with cancer, caregivers with unmet needs had a significantly higher burden [27].

Also, unmet needs have been correlated with age, sex, and education. That is, younger caregivers reported greater unmet needs than older caregivers $[28,29]$. Other associations with higher unmet needs were female gender, high risk for depression, and anxiety [30].

\section{Patient's quality of life}

Patient's quality of life may also influence caregiver burden. It measures an individual's functional status and their appraisal of their life quality. Caring for a spouse with cancer with poor 
quality of life may lead to a high caregiving demand, resulting in higher burden. A better understanding of the caregiver burden in esophageal cancer may assist health care professionals in providing resources to caregivers most in need.

In this exploratory study, we will (1) examine caregiver burden of spousal caregivers of patients with esophageal cancer after curative treatment with neoadjuvant chemoradiation followed by resection, and (2) examine the extent to which caregiver burden is associated with demographics of the patient and caregiver, depressive symptoms or anxiety of the patient and the caregiver, marital satisfaction, caregiver's unmet needs, and patient's quality of life.

\section{Methods}

\section{Participants}

Caregivers and patients with esophageal cancer were eligible when patients were treated with neoadjuvant chemoradiation followed by resection [3], in the Academic Medical Center (AMC) between 2009 and 2013. At the moment of inclusion, the resection should have been performed at least 1 year with a maximum of 5 years previously. The patient had to be free of metastases or local recurrence. The patient had to have a spousal caregiver. Partners could be included if they had been the patients' intimate partner from the moment of surgery until the moment of inclusion. All eligible patients and partners were Dutch-speaking and living in the Netherlands.

\section{Procedure}

All potential patients were identified from the surgery database of our hospital. The patients and their caregivers were contacted by phone. After informed consent, patients and their caregivers received a questionnaire by post. Patients and caregivers received a telephone reminder after 2 weeks, if the questionnaires had not been sent back. According to national regulations, formal ethics approval was not needed.

\section{Assessment of caregiver burden}

To assess caregivers' burden, all caregivers filled out the SelfPerceived Pressure from Informal Care (SPPIC) questionnaire, a validated Dutch self-report instrument to assess caregiving burden. It is a nine-item self-report Rasch scale that measures self-perceived pressure from informal care. The stress measured by SPPIC refers to the demands the spouse perceives with respect to the personal interests, the psychological and psychosocial complaints, and to the stressors in the caregiving situation. The SPPIC has a satisfactory index of subject separation of 0.66 (which indicates how well items discriminate between subjects) and a reliability (rho) of 0.79 .
Caregivers were asked to indicate the extent to which they agreed with nine statements using response options "No!; No; More or less; Yes or Yes!."

To score the SPPIC, item scores were dichotomized and summed subsequently. Scores 1 and 2 were recorded into 0 (i.e., not perceiving pressure), and scores 3 , 4, and 5 were recorded into 1 (i.e., perceiving pressure). Scores range from 0 to 9 with higher scores indicating more pressure.

A score between 0 and 3 indicates that a caregiver feels little burden; 4-6 indicates moderate burden; and 7-9 indicates high burden [31].

\section{Assessment of factors associated with caregiver burden}

\section{Demographic and clinical data}

Demographic data were collected from the patient and caregiver by self-report and included age, sex, education, and employment status. Date of esophageal resection was collected from the clinical chart.

\section{Anxiety and depressive symptoms}

Anxiety and depressive symptoms were measured with the Hospital Anxiety and Depression Scale (HADS) [32].

This self-administered questionnaire contains 14 items, which are divided in two subscales: HADS-A for anxiety and HADS-D for depression. Both contain seven questions and are presented in a mixed order. Items are rated on a four-point scale, rendering a maximum score of 21 points. Scores of 0-7 are considered normal. Scores of $\geq 11$ are considered a significant case for anxiety or depression. Scores 8 10 are considered "borderline" indicating potential clinical anxiety or depression.

\section{Quality of marital relationship}

The nature and quality of the marital relationship was evaluated by the Maudsley Marital Questionnaire (MMQ), which was filled out by both patients and caregivers. The MMQ contains 20 items, which are combined to form three scales: marital (M), sexual (S), and general life (GL). The marital scale assesses marital satisfaction. Response options range from $0=$ very satisfied to $8=$ we never reach an agreement. To exemplify, "how satisfied are you with living with your partner?" The general life scale evaluates emotional aspects of the relationship.

The sum scores of the marital (ten items), sexual (five items), and general life (five items) scales, respectively, range $0-80,0-40$, and $0-40$ [1]. A high score on the subscales reflects high discontent. A cutoff point of $\geq 20$ was used to indicate maladjustment in the $\mathrm{M}$ scale $[33,34]$. For the $\mathrm{S}$ and GL scales, no cutoff point is described in literature and therefore not used. 


\section{Unmet needs}

Caregivers' unmet needs were examined by the Supportive Care Needs Survey-Partners and Caregivers (SCNS-P\&C) which contains 44 unmet needs [14, 35]. Needs were assigned to four domains: health care service, psychological and emotional, work and social needs, and informational needs. Caregivers were asked to indicate to which degree they needed help with each item. Questions could be answered on a five-point Likert scale with not applicable or fulfilled (response 1 or 2 , respectively) versus needs that remain unsatisfied (response options 3-5, i.e., low, moderate, or high unmet needs). Cutoff was set on item level. We dichotomized the scale into "no need" versus "any need."

\section{Patients' quality of life}

To assess quality of life of the patient, the EORTC-QLQ C30 and the esophageal site-specific module OES18 were used $[36,37]$. Raw scores were calculated as described in the EORTC scoring manual. All scores ranged from 0 to 100. Both questionnaires contain functional scales and symptom scales. Higher scores on functional scales indicate a better functioning, while higher scores on symptom scales indicate a higher symptom burden.

\section{Statistical analysis}

1. Descriptive statistics were performed to describe all studied variables. Quality of life scores were analyzed per change of 10 in both scores, assuming changes of 10 being clinically relevant [38].

2. Caregiver burden as measured by SPPIC, the dependent variable in our study, was dichotomized into low burden (0-3 points) or moderate to high burden (4-9 points), taking together moderate (4-6) and high (7-9) burden.

3. Univariate logistic regression analysis was performed to explore factors associated with caregiver burden, defined as the dichotomized SPPIC score.

4. To select the appropriate variables for the multivariate analysis, we selected those parameters that showed both a significant univariate association with caregiver burden and the strongest association with caregiver burden. This condition was used to decrease the total number of covariates in the multivariate model, under the assumption that the number of covariates should be approximately $10 \%$ of the events (event=having moderate or high burden) [39]. Based on the sample size of $n=47$ and the rule of a minimum observation-to-covariate ratio of 10:1, only four independent variables could be included in the multivariate analysis.

5. Correlation with Spearman's rho was performed to examine possible multicollinearity between covariates. A
Spearman's rho between -0.7 and 0.7 was considered as no clinically relevant multicollinearity.

6. Stepwise multivariate logistic regression analysis was performed to identify those variables that were independently associated with caregiver burden. The dichotomized SPPIC was the "dependent variable," and the four variables selected from the univariate logistic regression analysis were the "covariates."

7. To examine possible effect modification between the independently associated covariates of caregiver burden, multivariate logistic regression analysis was performed with an interaction term based on the covariates in the regression model. A statistically significant interaction term was considered as effect modification or interaction.

Odds ratios (ORs) with $95 \%$ confidence intervals (CIs) were provided for both caregiver and patient factors. All statistical analyses were conducted using Statistical Package for Social Sciences (SPSS), version 21. A $p$ value of 0.05 was considered statistically significant.

\section{Results}

During the study period, 248 patients underwent esophagectomy. Two hundred patients were treated with neoadjuvant chemoradiation. Hundred patients had died before start of the study, while 18 patients had developed metastatic disease. Of the remaining 82 patients, 15 patients could not be reached by telephone. Twelve patients did not have a spousal caregiver and could therefore not be included. Eight patients declined participation. Therefore, 47 couples were included in the study. The corresponding response rate was $67 \%$ (Fig. 2)

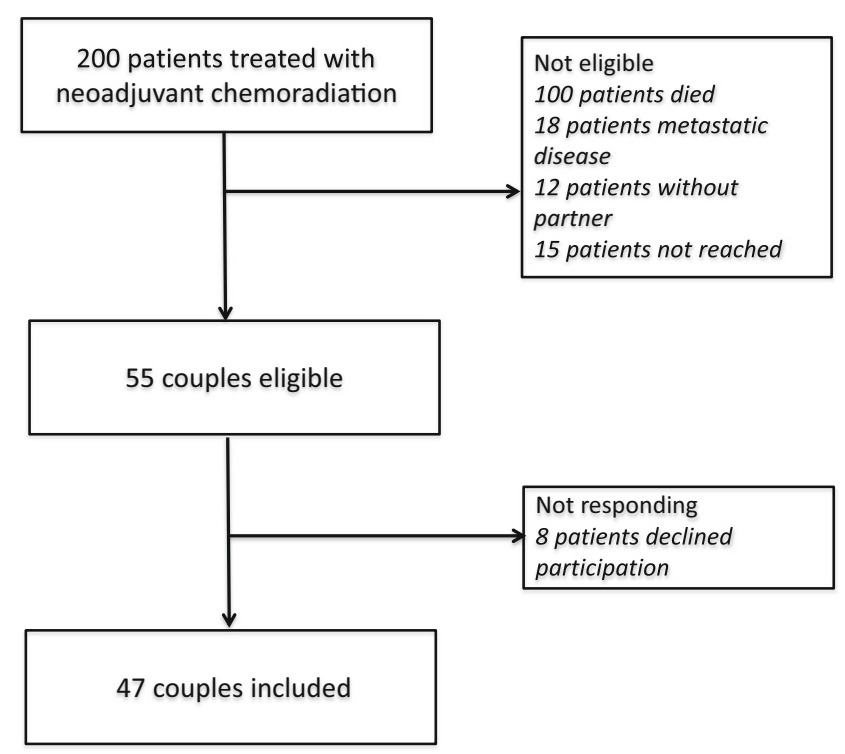

Fig. 2 Flow diagram for patients treated with neoadjuvant chemoradiation 


\section{Demographics}

On average, couples filled out the questionnaire 38 months $(\mathrm{SD}=9.2)$ after surgery.

The mean age of the caregivers was 64.4 years $(\mathrm{SD} \pm 7.2$; range 50-79), and they were predominantly females. Patients were on average 65.8 years $(\mathrm{SD}=7.2$; range $48-80)$ old and predominantly male. Median interval between surgery and questionnaire was 3 years.

Participants' characteristics are listed in Table 1.

\section{Caregiver burden}

Using the EDIZ caregiver scale, 15 (34\%) of the spousal caregivers reported a moderate or high burden (moderate burden $15 \%$, high burden $19 \%$ ). Low burden was reported by 31 (66\%) of the caregivers, 11 (23\%) of who reported no burden at all. The median score was 3 points (IQR $1-4$, indicating low burden.

\section{Factors associated with caregiver burden}

Anxiety and depressive symptoms A similar proportion of spousal caregivers and patients $8(17 \%)$ were considered borderline or significant cases for anxiety. A similar proportion of caregivers and patients scored 11 points or higher on the depression scale and were considered significant cases for depression (2 vs 4 ) (Table 2).

Table 1 Demographiccharacteristics

\begin{tabular}{lll}
\hline & $\begin{array}{l}\text { Caregiver, } n=47 \\
(\%)\end{array}$ & $\begin{array}{l}\text { Patient, } n=47 \\
(\%)\end{array}$ \\
\hline $\begin{array}{l}\text { Mean age (SD) } \\
\text { Female gender }\end{array}$ & $\begin{array}{l}64.4(7.4) \\
33(70 \%)\end{array}$ & $\begin{array}{l}65.8(7.2) \\
13(28 \%)\end{array}$ \\
$\begin{array}{l}\text { Months between surgery and receiving } \\
\text { the questionnaire (mean (SD)) }\end{array}$ & $38(9.2)$ & \\
Children living at home yes & $5(11)$ & \\
Employment status & & \\
$\quad$ Full-time work & $6(13)$ & 0 \\
Part-time work & $11(23)$ & $11(23)$ \\
$\quad$ Retired & $18(38)$ & $8(17)$ \\
$\quad$ Unemployed & $6(13)$ & $9(19)$ \\
Educational status & & $3(6)$ \\
$\quad$ Low level & $3(6)$ & $21(45)$ \\
Intermediate level & $20(43)$ & $12(26)$ \\
High level & $11(23)$ & $11(23)$ \\
Advanced level & $12(26)$ &
\end{tabular}

Educational status: low level=elementary school; intermediate level= vocational education; high level=high school and college; advanced level=university
Table 2 Hospitality Anxiety and Depression Scale and Maudsley Martial Questionnaire of caregivers and patients reported as frequency (percentage) unless otherwise stated

\begin{tabular}{lll}
\hline & $\begin{array}{l}\text { Caregiver } \\
N=47(\%)\end{array}$ & $\begin{array}{l}\text { Patient } \\
N=47(\%)\end{array}$ \\
\hline Anxiety & & \\
$\quad$ HADS A 0-7 No anxiety & $36(77)$ & $39(83)$ \\
HADS A 8-10 Borderline anxiety & $8(17)$ & $4(9)$ \\
HADS A 11-20 Significant case & $3(6)$ & $4(9)$ \\
$\quad$ for anxiety & & \\
Depression & $41(87)$ & $41(87)$ \\
$\quad$ HADS D 0-7 No depression & $5(11)$ & $4(9)$ \\
$\quad$ HADS D 8-10 Borderline & $1(2)$ & $2(4)$ \\
$\quad$ depression & $8(3-21)$ & $5(4-14)$ \\
$\quad$ HADS D 11-20 Significant case & $13(28)$ & $6(13)$ \\
for depression & $14(9-25)$ & $14(7-21)$ \\
$\quad$ Marital dissatisfaction & $6(4-11)$ & $8(5-11)$ \\
$\quad \begin{array}{l}\text { Mean sexual scale mean (SD) } \\
\text { Median general life scale median (IQR) }\end{array}$ &
\end{tabular}

HADS A Hospitality Anxiety and Depression Scale anxiety subscale, HADS D Hospitality Anxiety and Depression Scale depression subscale

Quality of marital relationship Spousal caregivers' median score on the general life scale was 8 points (IQR 3-21, range $0-66$ points). This was not significantly higher $(p=0.422)$ than the median patients' score of 5 (IQR 3-14, range 0-63). On the sexual scale spousal caregivers and patients scored comparable (mean score caregiver 16 (SD 10), mean score patient 14 (SD 9)). Spousal caregivers reported significantly more martial dissatisfaction than patients (28 vs $13 \%$ ) (Table 2).

Unmet needs The top ranking of unmet needs of spousal caregivers were as follows: managing concerns about the cancer coming back (43.4\%), dealing with others not acknowledging the impact on your life of caring for a person with cancer (37.2\%), and balancing the needs of the person with cancer and your own needs (33.3\%). The top three ranking of all needs were all part of the "psychosocial and emotional" domain. When selecting only moderate and high needs, these needs were in de "health care service" domain [14]. The median number of unmet needs noted by caregivers was 2.0 (range $0-40$, interquartile range). The proportion of caregivers reporting at least one unmet need in the SCNS was $66 \%$, at least two unmet needs $55 \%$, at least three unmet needs $49 \%$. Notably, $38 \%$ of the caregivers reported more than ten unmet needs and a comparable proportion (34\%) no unmet needs.

Patients' quality of life Patients had a median global health score of 83 (IQR=6-83). Median scores for role and social functioning were maximal. Except for fatigue all symptom scales showed a median score of zero. The site-specific 
module (OES 18) showed that patients had complaints of dysphagia, problems with eating, reflux, dry mouth, and coughing (Table 3 ).

Factors associated with caregiver burden Table 4 depicts the all factors associated with caregiver burden. Negative associations for caregiver burden were fatigue of the patient (OR $1.64,95 \%$ CI 1.18-2.28) and HADS D of the spousal caregiver (OR 1.48, $95 \%$ CI 1.16-1.89). While cognitive functioning (OR 0.68, $95 \%$ CI 0.50-0.92), emotional functioning (OR 0.67, $95 \%$ CI $0.50-0.90$ ) and social functioning of the patient (OR $0.64,95 \%$ CI $0.47-0.87$ ) were inversely associated with the presence of caregiver burden. Based on the sample size of $n=47$ and the rule of a minimum observation-topredictor ratio, only four predictors were included in the multivariate analysis, i.e., caregiver's depression, patient's fatigue, patient's social functioning, and patient financial problems.

Table 3 EORTC Quality of life scores C30 and OES18 of patients

\begin{tabular}{|c|c|}
\hline QLQ-C30 (median with IQR) & Patients $(N=47)$ \\
\hline Global health score & $83(6-83)$ \\
\hline \multicolumn{2}{|l|}{ Functional scales } \\
\hline Physical functioning & $87(80-100)$ \\
\hline Role functioning & $100(67-100)$ \\
\hline Emotional functioning & $92(75-100)$ \\
\hline Cognitive functioning & $100(67-100)$ \\
\hline Social functioning & $100(67-100)$ \\
\hline \multicolumn{2}{|l|}{ Symptom scales } \\
\hline Fatigue & $33(11-44)$ \\
\hline Nausea/Vomiting & $0(0-17)$ \\
\hline Pain & $0(0-33)$ \\
\hline Dyspnea & $0(0-33)$ \\
\hline Appetite loss & $0(0-33)$ \\
\hline Constipation & $0(0-33)$ \\
\hline Diarrhea & $0(0-33)$ \\
\hline Financial problems & $0(0)$ \\
\hline \multicolumn{2}{|l|}{ QLQ-OES18 } \\
\hline Dysphagia & $22(0-33)$ \\
\hline Problems with eating & $17(8-50)$ \\
\hline Reflux & $16(0-50)$ \\
\hline Pain & $0(0-11)$ \\
\hline Trouble swallowing saliva & $0(0-33)$ \\
\hline Choked when swallowing & $0(0-33)$ \\
\hline Dry mouth & $33(0-33)$ \\
\hline Trouble with taste & $0(0-33)$ \\
\hline Trouble with coughing & $33(0-67)$ \\
\hline Trouble with talking & $0(0-8)$ \\
\hline
\end{tabular}

QLQ-C30 European Organization of Research and Treatment of Cancer Quality of Life Questionnaire Cancer-30, QLQ-OES18 European Organization of Research and Treatment of Cancer Quality of Life Questionnaire Oesophagus-18
Stepwise backward elimination including significant variables from the univariate model resulted in a final model with caregiver's depression $(\mathrm{OR}=1.44,95 \% \mathrm{CI} 1.11-1.86)$ and a tenpoint increase of fatigue of the patient $(\mathrm{OR}=1.66,95 \% \mathrm{CI}$ 1.12-2.47) as correlates for caregiver burden.

Clinically relevant correlations between the four selected variables of the multivariate analysis were not found. Borderline correlation was found between patient's fatigue and patient's social functioning (Supplementary Table 1).

No statistically significant effect modification (interaction) between covariates was found.

We reanalyzed the data with a SPPIC cutoff of 6 , taking together low and moderate burden. None of the variables showed a significant correlation with caregiver burden.

\section{Discussion}

This study is the first to provide data on the burden of spousal caregivers caring for patients with resectable esophageal cancer, on average 3 years after patients' surgery.

We demonstrated that one third of the spousal caregivers experienced moderate or high burden (moderate $15 \%$, high $19 \%$ ). This proportion was comparable to caregivers of patients with colorectal cancer [40], but higher than caregivers of patients who had head and neck cancer and were treated with radiation/chemoradiation [41]. It is important to realize that we investigated a selection of all patients with esophageal cancer, namely the patients that were treated with curative intent and are still alive 3 years after their treatment. Most research has focused on caregivers providing care during active treatment or at the patient's end of life. However, informal care giving continues with the completion of the patient's active treatment [13]. Given the median time of 38 months after esophagectomy, the burden of spousal caregivers in the context of accelerated hospital discharge and critical participation in care service was not under investigation in this study.

Fatigue of the patient was a significant factor associated with caregiver burden, with an almost $70 \%$ increase in risk of caregiver burden, while age, employment, education level, quality of marital relationship, and unmet needs had no impact on caregiver burden. Next to fatigue of the patient, depression of the caregiver increased the risk of burden with almost $40 \%$.

Cancer survivors have extensively described fatigue as a distressing symptom in general $[42,43]$. It occurs in at least 30 to $40 \%$ of the cancer survivors. In a recent meta-analysis in patients after esophagectomy, it was shown that fatigue lasted for more than 12 months after surgery [44]. Publications concerning interventions on fatigue are numerous. Pharmacologic and nonpharmacologic interventions have been shown to be effective for relieving or managing fatigue [45]. A study conducted in 98 disease-free cancer patients with severe fatigue showed that postcancer fatigue can be 
Table 4 Univariate logistic regression analysis, factors associated with caregiver burden

\begin{tabular}{|c|c|c|c|c|}
\hline \multirow[b]{2}{*}{ Variable } & \multicolumn{2}{|l|}{ Caregiver } & \multicolumn{2}{|l|}{ Patient } \\
\hline & Odds ratio & $95 \% \mathrm{CI}$ & Odds ratio & $95 \% \mathrm{CI}$ \\
\hline Increasing age (per year) & 0.95 & $0.87-1.03$ & 0.94 & $0.85-1.03$ \\
\hline Male gender & 0.42 & $0.10-1.80$ & 1.59 & $0.36-6.98$ \\
\hline Increasing time since resection (per month) & 0.98 & $0.91-1.04$ & & \\
\hline Increasing total unmet needs (per one) & 1.08 & $1.01-1.15$ & & \\
\hline \multicolumn{5}{|l|}{ Education } \\
\hline Low level & 1.00 & $0.68-14.64$ & 2.25 & $0.13-38.81$ \\
\hline Intermediate level & 0.67 & $0.14-3.20$ & 2.25 & $0.38-13.35$ \\
\hline High level & 0.75 & $0.13-4.49$ & 2.25 & $0.32-15.76$ \\
\hline Advanced level & Ref & & Ref & \\
\hline \multicolumn{5}{|l|}{ Employement status } \\
\hline Full time & 1.00 & $0.05-20.83$ & na & \\
\hline Part time & 2.86 & $0.24-33.90$ & 1.14 & $0.18-7.28$ \\
\hline Retired & 1.92 & $0.18-20.82$ & 0.67 & $0.08-5.54$ \\
\hline Other & 5.00 & $0.34-72.77$ & 0.71 & $0.13-4.00$ \\
\hline Unemployed & Ref & & Ref & \\
\hline Employement hours & 0.88 & $0.44-1.79$ & 1.72 & $0.67-4.41$ \\
\hline HADS A & 1.36 & $1.10-1.67^{*}$ & 1.13 & $0.95-1.34$ \\
\hline HADS D & 1.48 & $1.16-1.89^{*}$ & 1.20 & $0.98-1.44$ \\
\hline MMQ dissatisfaction & 0.31 & $0.08-1.17$ & 1.04 & $0.17-6.38$ \\
\hline \multicolumn{5}{|l|}{ QLQ-C30 } \\
\hline Global Health score & & & 0.71 & $0.50-1.00^{*}$ \\
\hline Physical function & & & 0.75 & $0.50-1.12$ \\
\hline Role function & & & 0.78 & $0.59-1.01$ \\
\hline Cognitive function & & & 0.68 & $0.50-0.92 *$ \\
\hline Emotional function & & & 0.67 & $0.50-0.90^{*}$ \\
\hline Social function & & & 0.64 & $0.47-0.87 *$ \\
\hline Fatigue & & & 1.64 & $1.18-2.28^{*}$ \\
\hline Nausea & & & 1.13 & $0.90-1.42$ \\
\hline Pain & & & 1.25 & $0.96-1.62$ \\
\hline Dyspnea & & & 1.19 & $0.93-1.52$ \\
\hline Appetite loss & & & 1.24 & $1.03-1.49^{*}$ \\
\hline Constipation & & & 1.08 & $0.83-1.39$ \\
\hline Diarrhoea & & & 1.27 & $0.94-1.72$ \\
\hline Financial problems & & & 1.53 & $1.05-2.22 *$ \\
\hline \multicolumn{5}{|l|}{ QLQ-OES 18} \\
\hline Dysphagia & & & 1.18 & $0.98-1.43$ \\
\hline Problems with eating & & & 1.04 & $0.83-1.31$ \\
\hline Reflux & & & 1.30 & $1.05-1.62 *$ \\
\hline Pain & & & 0.99 & $0.74-1.31$ \\
\hline Trouble swallowing saliva & & & 1.05 & $0.89-1.23$ \\
\hline Choked when swallowing & & & 1.14 & $0.93-1.41$ \\
\hline Dry mouth & & & 1.02 & $0.83-1.26$ \\
\hline Trouble with taste & & & 1.14 & $0.93-1.40$ \\
\hline Trouble with coughing & & & 1.19 & $0.98-1.46$ \\
\hline Trouble with talking & & & 0.99 & $0.77-1.27$ \\
\hline
\end{tabular}

Educational status: low level, elementary school; intermediate level, vocational education; high level, high school and college; advanced level, university

Ref reference, HADS A Hospital Anxiety and Depression Scale subscale anxiety, HADS D Hospital Anxiety and Depression Scale subscale depression, $M M Q$ Maudsley Marital Questionnaire, $Q L Q$-C30 European Organization of Research and Treatment of Cancer Quality of Life Questionnaire Cancer-30, QLQ-OES18 European Organization of Research and Treatment of Cancer Quality of Life Questionnaire Oesophagus-18

*Significant 
treated effectively with cognitive behavioral therapy [46]. The current study demonstrated that treating fatigue may not only alleviate patients' distress but may also decrease caregivers' burden. The reasons for the strong relation between fatigue and caregiver burden should be addressed in future qualitative research. Possibly, patients' fatigue limits their capacity to perform self-care or household activities and their ability to join leisure activities, which increases caregiver's burden. Supporting spousal caregivers should involve helping them manage the fatigue of their partner.

Patients' quality of life in general was very good as indicated by the mean general health score of 83 and median scores of the functional scales of at least 87 . Even on the symptom scales measured by EORTC QLQ-C30 $50 \%$ of the patients showed no complaints. However, when using the esophageal specific site module symptom scores, indeed showed the presence of symptoms. These findings correspond with the recently reported deterioration in aspects of quality of life several months after esophageal cancer surgery [44].

Our results showed that caregiver's depression was associated with the presence of moderate and high burden. Our estimates of depression in caregivers and patients are lower than those in some previous reports. This is probably caused by the fact that our study was performed a relatively long time since resection (mean 38 months). A recently published review on depression and anxiety in cancer survivors and their spouses illustrates the heterogeneity of the results regarding the prevalence of derpression [47]. In the pooled sample of 1 , 285 caregivers a prevalence of depression of $26.3 \%$ with a $95 \%$ CI of 18.4-35.0 was reported. Of note, not all studies used the HADS questionnaire for measuring symptoms of depression. Length of time since diagnosis was 4.35 years (standard deviation 1.67). Despite the relatively low rate of depression symptoms in our sample, it turned out to be a correlate of caregiver burden. Our study does not allow for conclusions about the cause of caregiver's depression, and it cannot rule out the possibility that it is caregiver burden that causes depression, rather than vice versa. It does show, however, that spousal caregivers with depressive symptoms are likely to coexperience caregiver burden, which might direct caregiver support. Indisputable, the treatment of esophageal cancer has been improved during the previous 10 years. Nevertheless, the recurrence rate remains $35 \%$ with the dismal median prognosis of 49.4 months [48]. Therefore, the cancer coming back is not unrealistic and explicit handling of this topic during consultation may support patients and caregivers. Despite the significant psychological impact of caring, caregivers might not seek required treatment, as Vanderwerker et al. [49] reported that almost half of cancer caregivers who met diagnostic criteria for a psychiatric condition did not seek treatment.

In our study, spousal caregivers reported significantly more martial dissatisfaction than patients. This corresponds to previous reports. Langer et al. [50, 51] found that caregivers reported lower levels of marital satisfaction 1.5 years after stem cell transplant. In their data, with a balanced gender distribution, the predictor for martial dissatisfaction was female gender of the caregiver. The spousal caregivers in our study are predominantly female $(70 \%)$ which may have added to the significantly high dissatisfaction.

We showed that managing concerns about the cancer coming back (43.4\%), dealing with others not acknowledging the impact on your life of caring for a person with cancer (37.2\%), and balancing the needs of the person with cancer and your own needs were the top ranking unmet needs. This concurs well with previous report [52-54].

The first unmet need is in line with the high recurrence rate of esophageal cancer after treatment with curative intent. The frequency of this unmet need published in literature varies [54, 55] and as concluded by Harrison et al. [56] in their review, the absence of standard methods of analysis and reporting unmet needs prohibits analysis of unmet needs.

Some limitations of our study need to be acknowledged. First, this is a Dutch cohort from a tertiary center and therefore may not be representative for patients and spousal caregivers in other countries and other hospitals. Second, selection bias might have occurred. Although the response rate was relatively high (67\%), the sample of respondents can be a selection of spousal caregivers with a relatively low caregiver burden. Spousal caregivers encountering high burden might not want to participate in this trial. No nonresponder/refuser analysis was conducted. Third, due to its cross sectional design, causal relations cannot be inferred. Fatigue of the patient and depression of the spousal caregiver can influence caregiver burden, caregiver burden can also influence fatigue of the patient and depression of the caregiver. Fourth, the small sample size limits generalizability. A larger sample size would have allowed for a more extensive multivariate analysis [39]. Fifth, the SPPIC is a validated instrument, but standard data have not been established. The cutoff used for dichotomization of the SPPIC is not validated. However, as the presence of caregiver burden (yes/no) is useful information in the consultation room, we dichotomized the SPPIC. We used a low cutoff value in order to detect moderate and high burden. Since even moderate burden 3 years after treatment could be considered worrisome, we decided to split low from moderate-high burden.

Sixth, multicollinearity between covariates was assessed for the selected variables included in the multivariate analysis. Because of limited statistical power, extensive model checking was not possible. As clinically relevant correlations were not found, multicollinearity appeared not of major relevance. Seventh, as noninteraction of the correlates (caregiver's depression and patient's fatigue) is a prerequisite for reasonable interpretation of odds ratios in logistic regression, we performed multivariable regression analysis including an 
interaction term, which was not statistically significant associated with the outcome; however, it cannot be fully ruled out. And last, in our data, in which each patient is linked to a spousal caregiver, nonindependence cannot be assumed. Mutual influence within a patient and his/her spousal caregiver is present and possibly relevant in interpreting our results. Consequently, interferential test statistics may be too liberal or too conservative.

Despite these restrictions, our findings have useful clinical implications and provide a base for future research. Regression analysis identified a group of spousal caregivers at risk for experiencing higher burden. Our finding that patient's fatigue and caregiver's depression are associated with higher caregiver burden points to risk factors that are of direct use in the consultation room. The current practiced routine in the Netherlands unfortunately lacks structural attention for the spousal caregiver. Patients periodically have follow-up visits with health care providers who are focused primarily upon the physical needs of the patient. An incentive has recently been undertaken in the Netherlands to measure burden during the cancer treatment (Ontmoet je Partner in Zorg [Dutch; meet your partner in care] [57]). Utilizing psychological interventions such as psycho-education, counseling, or skills training have been shown to decrease symptoms of distress [8]. Unfortunately, these interventions are rarely implemented [8].

In conclusion, this is the first study reporting on caregiver burden in spousal caregivers of patients with esophageal cancer treated with curative intent. Our data show that more than a third of spousal caregivers of patients with esophageal cancer report moderate or high burden. Depression of the caregiver and fatigue of the patient are associated with caregiver burden. Further research should be undertaken to raise awareness and design interventions to reduce caregiver burden in esophageal cancer.

Conflict of interest The authors have declared no conflicts of interest.

Open Access This article is distributed under the terms of the Creative Commons Attribution-NonCommercial 4.0 International License (http:// creativecommons.org/licenses/by-nc/4.0/), which permits any noncommercial use, distribution, and reproduction in any medium, provided you give appropriate credit to the original author(s) and the source, provide a link to the Creative Commons license, and indicate if changes were made.

\section{References}

1. Ferlay J, Shin HR, Bray F, Forman D, Mathers C, Parkin DM (2010) Estimates of worldwide burden of cancer in 2008: GLOBOCAN 2008. Int J C J Int Canc 127:2893-2917

2. Napier KJ, Scheerer M, Misra S (2014) Esophageal cancer: a review of epidemiology, pathogenesis, staging workup and treatment modalities. World J Gastrointest Oncol 6:112-120
3. van Hagen P, Hulshof MC, van Lanschot JJ et al (2012) Preoperative chemoradiotherapy for esophageal or junctional cancer. N Engl J Med 366:2074-2084

4. Oppedijk V, van der Gaast A, van Lanschot JJ et al (2014) Patterns of recurrence after surgery alone versus preoperative chemoradiotherapy and surgery in the CROSS trials. J Clin Oncol Offic J Am Soc Clin Oncol 32:385-391

5. Romito F, Goldzweig G, Cormio C, Hagedoorn M, Andersen BL (2013) Informal caregiving for cancer patients. Cancer 119(Suppl 11):2160-2169

6. Blum K, Sherman DW (2010) Understanding the experience of caregivers: a focus on transitions. Semin Oncol Nurs 26:243-258

7. Nijboer C, Triemstra M, Tempelaar R, Sanderman R, van den Bos GA (1999) Determinants of caregiving experiences and mental health of partners of cancer patients. Cancer 86:577-588

8. Northouse L, Williams AL, Given B, McCorkle R (2012) Psychosocial care for family caregivers of patients with cancer. J Clin Oncol 30:1227-1234

9. Mitschke D (2008) Cancer in the family: review of the psychosocial perspectives of patients and family members. J Family Soc Work 11:166-84

10. Kurtz ME, Kurtz JC, Given CW, Given BA (2004) Depression and physical health among family caregivers of geriatric patients with cancer - a longitudinal view. Med Sci Mon Int Med J Exp Clin Res 10:CR447-CR456

11. van Ryn M, Sanders S, Kahn K et al (2011) Objective burden, resources, and other stressors among informal cancer caregivers: a hidden quality issue? Psychooncology 20:44-52

12. Zarit SH, Reever KE, Bach-Peterson J (1980) Relatives of the impaired elderly: correlates of feelings of burden. Gerontologist 20: 649-655

13. Given BA, Sherwood P, Given CW (2011) Support for caregivers of cancer patients: transition after active treatment. Canc Epidemiol Biomark Prevent Publ Am Assoc Canc Res Am Soc Prevent Oncol 20:2015-2021

14. Girgis A, Lambert S, Lecathelinais C (2011) The supportive care needs survey for partners and caregivers of cancer survivors: development and psychometric evaluation. Psychooncology 20:387-393

15. Blood GW, Simpson KC, Dineen M, Kauffman SM, Raimondi SC (1994) Spouses of individuals with laryngeal cancer: caregiver strain and burden. J Commun Disord 27:19-35

16. Zarit SH, Todd PA, Zarit JM (1986) Subjective burden of husbands and wives as caregivers: a longitudinal study. Gerontologist 26: 260-266

17. Given CW, Stommel M, Given B, Osuch J, Kurtz ME, Kurtz JC (1993) The influence of cancer patients' symptoms and functional states on patients' depression and family caregivers' reaction and depression. Health Psychol Offic J Div Health Psychol Am Psychol Assoc 12:277-285

18. Northouse LL (1995) The impact of cancer in women on the family. Cancer Pract 3:134-142

19. Braun M, Mikulincer M, Rydall A, Walsh A, Rodin G (2007) Hidden morbidity in cancer: spouse caregivers. J Clin Oncol 25: 4829-4834

20. Haun MW, Sklenarova H, Villalobos M et al (2014) Depression, anxiety and disease-related distress in couples affected by advanced lung cancer. Lung Cancer 86:274-280

21. Janda M, Steginga S, Langbecker D, Dunn J, Walker D, Eakin E (2007) Quality of life among patients with a brain tumor and their carers. J Psychosom Res 63:617-623

22. Sanson-Fisher R, Girgis A, Boyes A, Bonevski B, Burton L, Cook $\mathrm{P}$ (2000) The unmet supportive care needs of patients with cancer. Supportive Care Review Group. Cancer 88:226-237

23. Soothill K, Morris SM, Harman JC, Francis B, Thomas C, McIllmurray MB (2001) Informal carers of cancer patients: what 
are their unmet psychosocial needs? Health Soc Care Community 9:464-475

24. Hagedoorn M, Sanderman R, Bolks HN, Tuinstra J, Coyne JC (2008) Distress in couples coping with cancer: a meta-analysis and critical review of role and gender effects. Psychol Bull 134:1-30

25. Manne S (1998) Cancer in the marital context: a review of the literature. Cancer Invest 16:188-202

26. Northouse LL, Mood D, Templin T, Mellon S, George T (2000) Couples' patterns of adjustment to colon cancer. Soc Sci Med 50: 271-284

27. Fried TR, Bradley EH, O'Leary JR, Byers AL (2005) Unmet desire for caregiver-patient communication and increased caregiver burden. J Am Geriatr Soc 53:59-65

28. Puts MT, Papoutsis A, Springall E, Tourangeau AE (2012) A systematic review of unmet needs of newly diagnosed older cancer patients undergoing active cancer treatment. Support Care Canc Offic J Multination Assoc Support Care Canc 20:1377-1394

29. Smith DP, Supramaniam R, King MT, Ward J, Berry M, Armstrong BK (2007) Age, health, and education determine supportive care needs of men younger than 70 years with prostate cancer. J Clin Oncol Offic J Am Soc Clin Oncol 25:2560-2566

30. Lambert SD, Harrison JD, Smith E et al (2012) The unmet needs of partners and caregivers of adults diagnosed with cancer: a systematic review. BMJ Support Palliat Care 2:224-230

31. Pot AM, van Dyck R, Deeg DJH (1995) Ervaren druk door informele zorg: constructie van een schaal [Self-perceived pressure from informal care: construction of a scale]. Tijdschr Gerontol Geriatr 26:214-9

32. Zigmond AS, Snaith RP (1983) The hospital anxiety and depression scale. Acta Psychiatr Scand 67:361-370

33. Arrindell WA, Emmelkamp PM, Brilman E, Monsma A (1983) Psychometric evaluation of an inventory for assessment of parental rearing practices. A Dutch form of the EMBU. Acta Psychiatr Scand 67:163-177

34. Arrindell WA, Schaap C (1985) The Maudsley Marital Questionnaire (MMQ): an extension of its construct validity. Br J Psychiatr 147:295-299

35. Bonevski B, Sanson-Fisher R, Girgis A, Burton L, Cook P, Boyes A (2000) Evaluation of an instrument to assess the needs of patients with cancer. Supportive Care Review Group. Cancer 88:217-225

36. Blazeby JM, Conroy T, Hammerlid E et al (2003) Clinical and psychometric validation of an EORTC questionnaire module, the EORTC QLQ-OES18, to assess quality of life in patients with oesophageal cancer. Eur J Canc 39:1384-1394

37. Aaronson NK, Ahmedzai S, Bergman B et al (1993) The European Organization for Research and Treatment of Cancer QLQ-C30: a quality-of-life instrument for use in international clinical trials in oncology. J Natl Canc Inst 85:365-376

38. Waddell TS (2014) Quality of life (QoL) analysis from the randomized phase III REAL3 trial of epirubicin, oxaliplatin, and capecitabine (EOC) with or without panitumumab $(\mathrm{P})$ in advanced esophagogastric adenocarcinoma. J Clin Oncol 32:5s (suppl; abstr 4067)

39. Peduzzi P, Concato J, Kemper E, Holford TR, Feinstein AR (1996) A simulation study of the number of events per variable in logistic regression analysis. J Clin Epidemiol 49:1373-1379

40. Landsbergen KM, Prins JB, Brunner HG et al (2012) Psychological distress in newly diagnosed colorectal cancer patients following microsatellite instability testing for Lynch syndrome on the pathologist's initiative. Fam Cancer 11:259-267
41. Nightingale CL, Lagorio L, Carnaby G (2014) A prospective pilot study of psychosocial functioning in head and neck cancer patientcaregiver dyads. J Psychosoc Oncol 32:477-492

42. Prue G, Rankin J, Allen J, Gracey J, Cramp F (2006) Cancer-related fatigue: a critical appraisal. Eur J Canc 42:846-863

43. Servaes P, Verhagen C, Bleijenberg G (2002) Fatigue in cancer patients during and after treatment: prevalence, correlates and interventions. Eur J Canc 38:27-43

44. Jacobs M, Macefield RC, Elbers RG et al (2014) Meta-analysis shows clinically relevant and long-lasting deterioration in healthrelated quality of life after esophageal cancer surgery. Qual Life Res 23:1155-1176

45. Koornstra RH, Peters M, Donofrio S, van den Borne B, de Jong FA (2014) Management of fatigue in patients with cancer - a practical overview. Canc Treat Rev 40:791-799

46. Gielissen MF, Verhagen S, Witjes F, Bleijenberg G (2006) Effects of cognitive behavior therapy in severely fatigued disease-free cancer patients compared with patients waiting for cognitive behavior therapy: a randomized controlled trial. J Clin Oncol 24:4882-4887

47. Mitchell AJ, Ferguson DW, Gill J, Paul J, Symonds P (2013) Depression and anxiety in long-term cancer survivors compared with spouses and healthy controls: a systematic review and metaanalysis. Lancet Oncol 14:721-732

48. Oppedijk V, van der Gaast A, van Lanschot JJ et al (2014) Patterns of recurrence after surgery alone versus preoperative chemoradiotherapy and surgery in the CROSS trials. J Clin Oncol 32:385-391

49. Vanderwerker LC, Laff RE, Kadan-Lottick NS, McColl S, Prigerson HG (2005) Psychiatric disorders and mental health service use among caregivers of advanced cancer patients. J Clin Oncol Offic J Am Soc Clin Oncol 23:6899-6907

50. Langer S, Abrams J, Syrjala K (2003) Caregiver and patient marital satisfaction and affect following hematopoietic stem cell transplantation: a prospective, longitudinal investigation. Psychooncology 12:239-253

51. Langer SL, Yi JC, Storer BE, Syrjala KL (2010) Marital adjustment, satisfaction and dissolution among hematopoietic stem cell transplant patients and spouses: a prospective, five-year longitudinal investigation. Psychooncology 19:190-200

52. Girgis A, Lambert SD, McElduff P et al (2013) Some things change, some things stay the same: a longitudinal analysis of cancer caregivers' unmet supportive care needs. Psychooncology 22: $1557-1564$

53. Hodgkinson K, Butow P, Hunt GE, Wyse R, Hobbs KM, Wain G (2007) Life after cancer: couples' and partners' psychological adjustment and supportive care needs. Support Care Canc Offic J Multination Assoc Support Care Canc 15:405-415

54. Molassiotis A, Wilson B, Blair S, Howe T, Cavet J (2011) Unmet supportive care needs, psychological well-being and quality of life in patients living with multiple myeloma and their partners. Psychooncology 20:88-97

55. Hodgkinson K, Butow P, Hunt GE, Pendlebury S, Hobbs KM, Wain G (2007) Breast cancer survivors' supportive care needs 210 years after diagnosis. Support Care Canc 15:515-523

56. Harrison JD, Young JM, Price MA, Butow PN, Solomon MJ (2009) What are the unmet supportive care needs of people with cancer? A systematic review. Support Care Canc 17:1117-1128

57. www.radboudumc.nl/OverhetRadboudumc/NieuwsEnMedia/ archief/Nieuwsarchief2014/December2014/Pages/ MantelzorgAcademiebeteremantelzorginhetziekenhuisenthuis. aspx. MantelzorgAcademie: betere mantelzorg in het ziekenhuis en thuis. 2014 